\title{
Cultural Acceptance Differences of Renewable Energy Technologies
}

\author{
Ignas Mikalauskas and Asta Mikalauskienè
}

\begin{abstract}
$-21^{\text {st }}$ century life without the common technologies, such as a computer, mobile phone, automobile and others, is no longer imaginable. The invention, adaptation and mass production of these new technologies is a key and essential to further human development and survival on earth. Renewable energy technologies have been developed in order to have a sustainable, clean future with limitless energy source.

All of the past, present and future technologies are not linear in time when it comes to reaching different cultures and societies. Some of the cultures receive these new renewable energy technologies in a very much different order therefore there is a great change in how these cultures and societies perceive and accept the changes in their common day lives.

This paper focuses on identifying and presenting the cultural acceptance differences that occur in different societies within the area of renewable energy technologies studies.
\end{abstract}

Index Terms-Cultural social differences, social acceptance, renewable energy technologies.

\section{INTRODUCTION}

Historically there has always been a great dis-balance between people living in different parts of the world, different cultures, religions and the basic understanding of the commons. Some cultures have risen before the others and vice versa, where the latter were always the ones who had to follow up. At modern times, the world as we see it has become more equal than it has ever been before in the history, having more perks than ever, but also facing certain distinctive problems.

One of the main problems discussed by scientists in every region of the world is the problem of sustaining the life on earth, or sustainability. Sustainability has been first laid as a concept in the Brundtland Report of 1987 where concerns arose regarding the future, a better life for mankind, where the current generation would have to use fewer resources in order for future generations to have enough resources left [1].

Throughout time the idea has manifested and now the concept of sustainability and sustainable development states that there are three key dimensions - social, economic and environmental [2].

Regarding the acceptance of renewable energy technologies for different cultures, we are looking at all three of the previously mentioned dimensions, all of which are further analyzed in detail throughout the paper. The social dimension is analyzed by understanding the social acceptance of renewable energy as a problem to many

Manuscript received October 15, 2017; revised December 17, 2017.

Ignas Mikalauskas and Asta Mikalauskiene are with Vilnius University, LT-44280, Kaunas, Lithuania (e-mail: ignas.mikalauskas@gmail.com, asta.mikalauskiene@knf.vu.lt). different layers of societies [3], [4]. The economic dimension is analyzed by how these different cultures and societies can economically benefit by disregarding fossil fuels and starting to build renewable energy plants and use renewable energy technologies [4]. While saving economic spending, there is also good to be done to nature and the environment by saving its natural resources and letting them replenish, meantime using renewable energy sources that cannot be depleted [4].

All of the mentioned may be a great idea, but many of this depends on whether or not the people in different cultures will accept the concepts of sustainability and sustainable development and will be quick enough to adapt to all of the upcoming new technological changes. This will put a difference between the quality of life for future generations to come therefore it is crucial to understand what makes people and the cultures they live in, accept and let in the changes to make the world better for everyone.

The aim of the study is to determine the relationship between differentiated cultures and their social acceptance towards renewable energy technologies.

Throughout the research, the following areas of the study are explained: differentiating of countries to segments of development; what are renewable energy technologies; how cultural and social acceptance interacts with technology acceptance model; cultural acceptance differences and the relationship between differentiated groups towards renewable energy technologies.

Proposed study hypothesis - higher development countries are more likely to accept technologies and start using them rather than countries that have weaker development according to human development index.

\section{Study BACKGROUND - DifFERENTIATING}

Differentiation is a sociological term in system theory. Looking at this theory, the main feature of contemporary society is the elevated process of structure differentiation as an action of dealing with the intricacy of its environment. This is achieved through the formation of sub-systems in an attempt to duplicate within a system or structure the difference between it (the system or structure) and the environment (where the system or structure is).

The differentiation action is a means of developing the intricacy of a system. This is because each sub-system can make different and various connections with alternative sub-systems. This allows there to be more variation within the system and this is in order to reply to the variation in the environment. Increased variation aided by differentiation grants better feedback to the environment and also allows for faster evolution, whether it is only social or also sociocultural, 
which is defined sociologically as an action of selection from that different variation; the more differentiation including all the variation that is available, the more improved the selection [5].

In the context of socially accepting renewable energy technologies, one has to have the knowledge and understanding, a certain level of society development and an appropriate income level therefore the differentiating in this case is done according to the level of education, life expectancy and income indexes by different world segments.

Human Development Index (HDI) is provided by United Nations development programme and consists of education index, life expectancy index and income index [6]. Following is the Table I with differentiated segments of the world by human development index in 2015 , which provides a basic background for further analysis.

TABLE I: HUMAN DEVELOPMENT GROUPS

\begin{tabular}{|c|c|c|c|c|}
\hline Group & $\begin{array}{l}\text { HDI } \\
\text { (value } \\
\text { ) }\end{array}$ & $\begin{array}{l}\text { Life } \\
\text { expectanc } \\
\text { y } \\
\text { at birth } \\
\text { (years) }\end{array}$ & $\begin{array}{l}\text { Mean } \\
\text { years } \\
\text { of } \\
\text { schooli } \\
\text { ng } \\
\text { (years) }\end{array}$ & $\begin{array}{l}\text { Gross } \\
\text { national } \\
\text { income } \\
\text { (GNI) per } \\
\text { capita } \\
\text { (2011 PPP } \\
\text { \$) }\end{array}$ \\
\hline $\begin{array}{l}\text { G1 - Very high } \\
\text { human } \\
\text { development }\end{array}$ & 0.892 & 79.4 & 12.2 & 39,605 \\
\hline $\begin{array}{l}\text { G2 - High } \\
\text { human } \\
\text { development }\end{array}$ & 0.746 & 75.5 & 8.1 & 13,844 \\
\hline $\begin{array}{l}\text { human } \\
\text { development }\end{array}$ & 0.631 & 68.6 & 6.6 & 6,281 \\
\hline $\begin{array}{l}\text { G4 - Low } \\
\text { human } \\
\text { development }\end{array}$ & 0.497 & 59.3 & 4.6 & 2,649 \\
\hline
\end{tabular}

Table I shows that there are 4 main development groups. We state the assumption that the more developed the people, the culture and society, the more likely they are going to bring in and accept the technologies or are more likely to do that over less developed people, cultures and societies. These groups divide up the world by their development levels and upon these groups we are projecting possible renewable energy technologies.

\section{RENEWABLE ENERGY TECHNOLOGIES}

Renewable energy technologies are divided into five main segments:

1. Solar

2. Wind

3. Water

4. Bio

5. Other (miscellaneous)

Solar technologies include thermal concentrated and non-concentrated energy plants and devices, photovoltaic, photo-electrochemical, thermo-photovoltaic, luminescent solar, thermo-electric and solar chemical energy plants and devices [7].

Wind technologies include horizontal and vertical axis wind turbines, concentrated wind technologies, various blade type wind turbines and wind belts [7].

Water technologies include hydroelectricity from dammed reservoirs, dam-less or run-of-the-river type of hydroelectric power plants, micro and pico hydro devices, hydrokinetic hydroelectricity, ocean tidal, ocean marine current, ocean wave and osmotic or salinity gradient power hydroelectric power plants as well as geothermal power plants [7].

Bio technologies include biomass - biogas and landfill gas, biomass alcohol biofuel, biodiesel, green diesel or renewable diesel, syngas, vegetable oil, hydrocarbon plants and bio-gasoline, pyrolysis derived fuels, solids, waste to energy and microbial fuel cell based bio energy power technologies, methods and devices.

There are also a list of unclassified renewable energy technologies - harvesting kinetic energy, micro-harvesting, energy storage based on chemical compounds of batteries or via mechanical process, thermal energy storage, smart grid energy storage and energy conservation - demand side management.

Fig. 1 depicts the world map with countries within the differentiated human development groups.

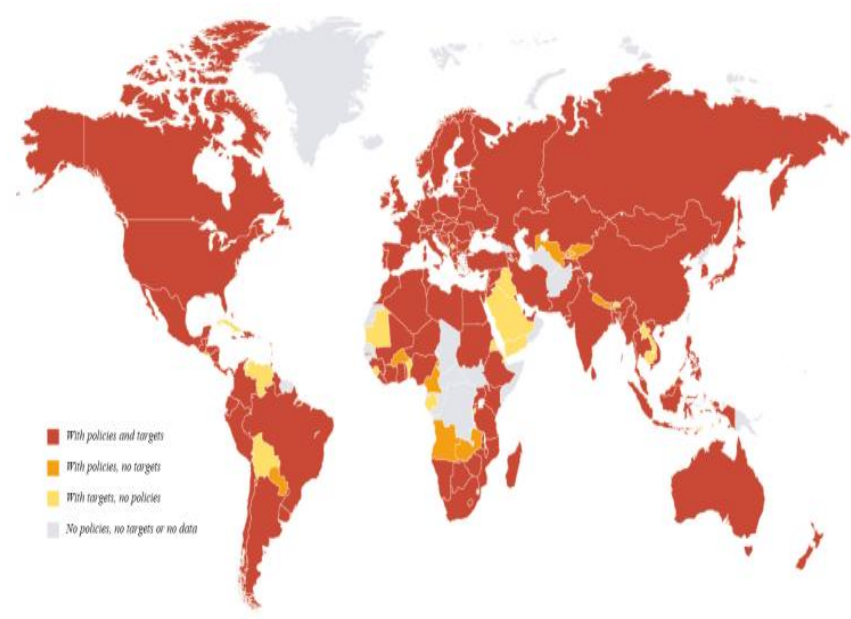

Fig. 1. Countries with renewable energy targets and policies, 2015, [8].

We see that nearly every culture in the world from the groups $1-4$ has renewable energy targets or policies, or both. This means that this is an ongoing process where every one of those countries can improve further the line and reach up higher level of development within in regards to renewable energy technologies.

In order to research and develop these technologies, there is a need for minimum special requirements - higher level of education, higher than average GDP balance science vise for innovations and the possibility to adapt the technologies to practice via natural availability.

Since there are a large variety of renewable energy technologies, we state the fact that there is at least a minimum of 1 possible renewable energy technology per group segment to be accepted, researched, developed and used.

These technologies are continued to being projected within the differentiated development groups and further mapped out within the limitations of the research. 


\section{Social ACCEPTANCE}

Social acceptance is measured within the boundaries of technology acceptance model, first presented in 1989 [9]. This model is being adjusted accordingly to suit the criteria that are set by human development index, current and future energy technology perspectives.

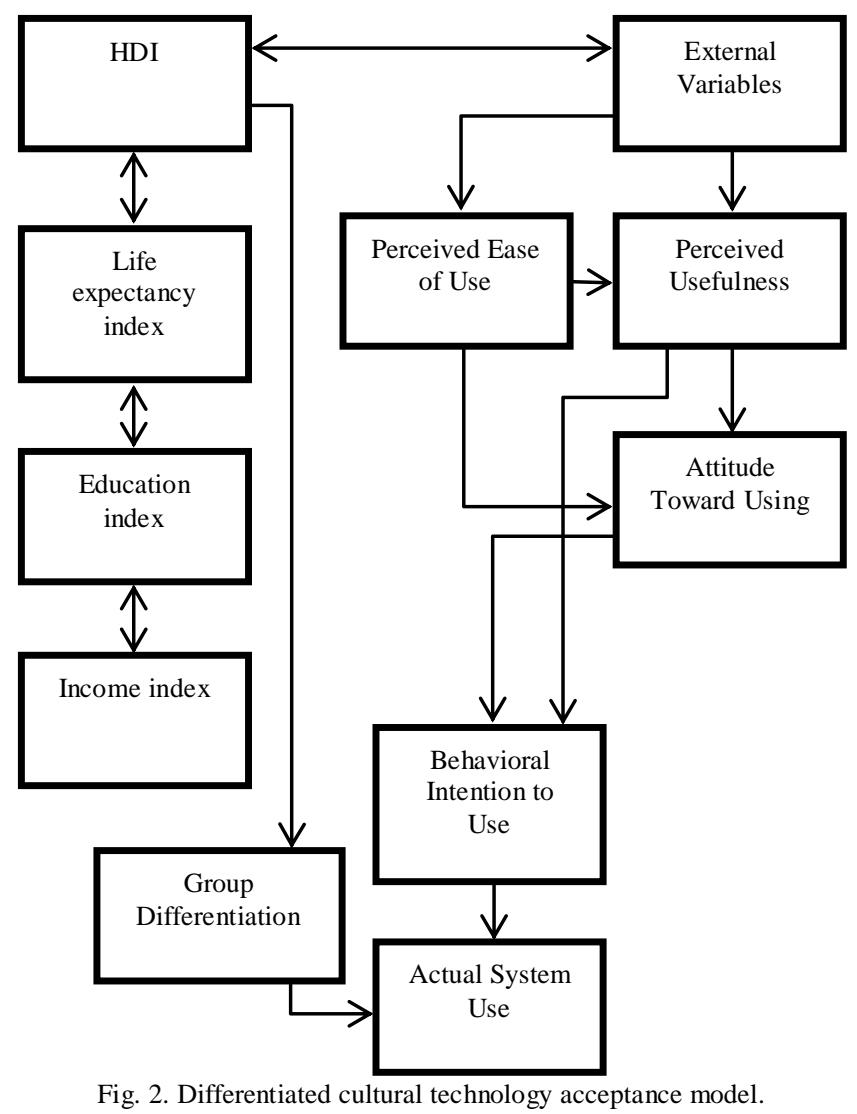

Fig. 2 details a picture of the relations between human development indexes and technology acceptance model and states that both of them are interactively connected with each other.

External variables in our study are all of the previously mentioned human development indexes combined in total. How one will perceive the technology and its usefulness will be determined on how well educated is that person and the culture he is in. Those people will also be more likely to have a positive attitude toward using because that will essentially give them the ability to achieve an economic prosperity.

This means that human development model in essence explains part of the technology acceptance model and can further be used and applied when projecting renewable energy technologies.

\section{Cultural Acceptance Differences}

According to previously stated hypothesis, it would be most likely that the top country by human development index would also be the top country to accept, obtain and start using a certain new renewable energy technology.

First measure is the percentage change of human development index within Groups 1 to 4 .

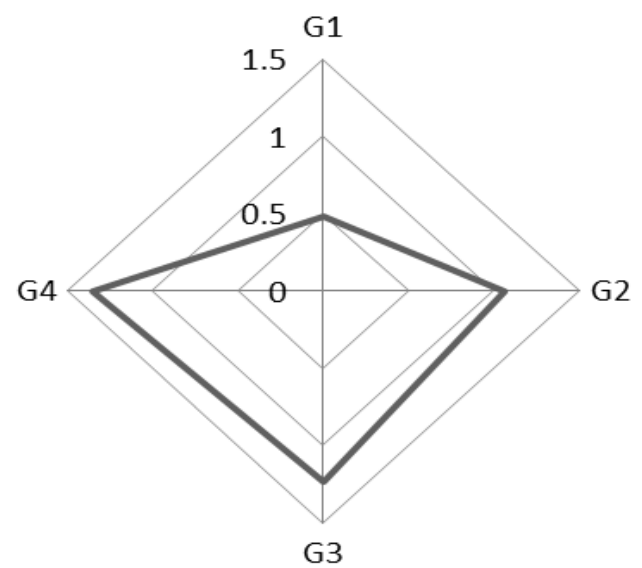

Fig. 3. The change of HDI between G1-4, 1990-2015, \%.

The change shows how each of the groups' human development index varied between the time span of 25 years. We see that G1 had the least advancement, following G2, G3 and G4. This means that the least advanced groups had and has the highest percentage of development and therefore this proves that the world balance is equalizing and more and more countries are becoming equal in terms of development, even if the distance between the top and bottom countries remains at large.

Following are Fig. 4-8 charts that each measure human development and a different sustainability criteria that is in need to achieve the required level of cultural acceptability for any of the groups G1-4 in regards with renewable energy technologies.

The HDI measurement is each time amplified in order to present visual data comparison over the selected criteria and represents the actual number in scale. Linear trend lines are added to sustainability lines in order to show the trends between different cultures. Interpretation of high-low lines is the visual understanding between the measurements and does not represent actual number in scale.

Fig. 4 shows the measure of human development index and renewable energy consumption as a percentage of total and final energy consumption in the year 2012.

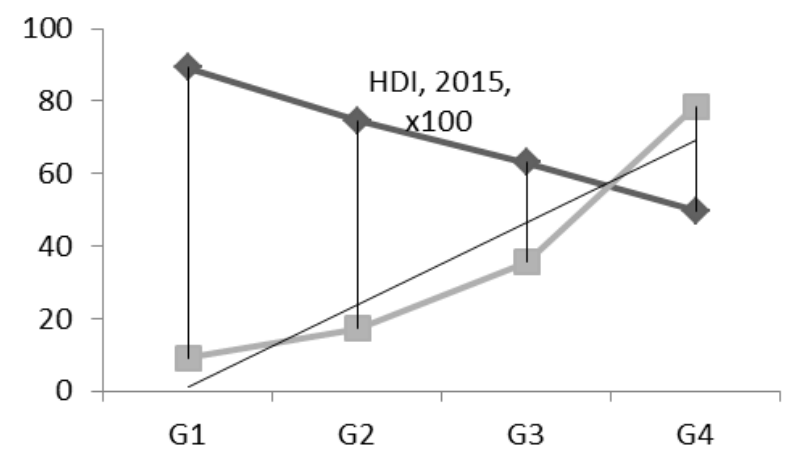

Fig. 4. HDI, 2015, x100 and Renewable energy consumption, (\% of total final energy consumption), 2012.

We see that the percent of renewable energy consumed in less developed countries is much greater than in higher development countries. This is natural and the reason for this happening is because higher developed countries have greater amounts of energy needed and therefore they require 
using non-renewable energy sources to fill in the gaps and peak demands for when energy is most needed. Also, there is the fact that higher developed groups have the highest amount of factories and machinery that runs on energy that supplies less developed countries with goods and services.

Anyhow, this shows us that higher developed countries in this case semi-denies the hypothesis and at the current state in the world, less developed countries have higher final energy consumption from renewable energy sources.

Fig. 5 shows the measure of human development index and carbon dioxide emissions per capita, in tons, at the year 2013.

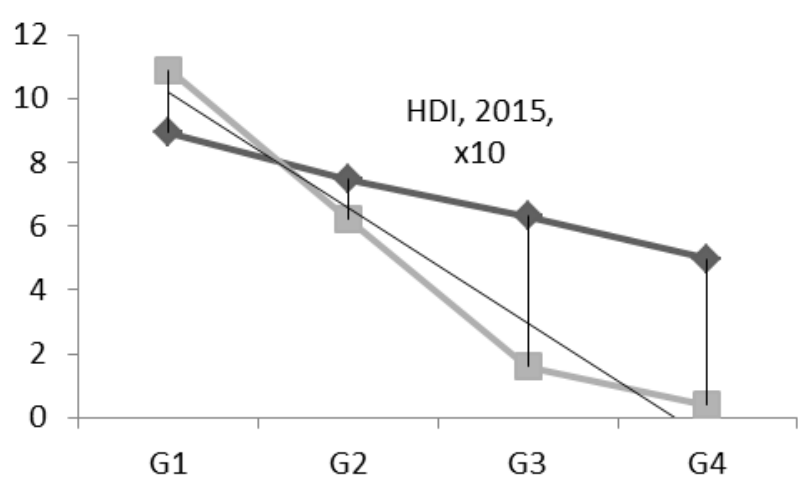

Fig. 5. HDI, 2015, x10 and Carbon dioxide emissions, Per capita (tonnes), 2013.

Carbon dioxide emissions show how much $\mathrm{CO}_{2}$ is released into the atmosphere from each of the groups. The higher the $\mathrm{CO}_{2}$ emission, the more non-renewable energy is being used in comparison with renewable energy use. In an ideal situation, $\mathrm{CO}_{2}$ emissions would zero out and show a flat line.

When looking at carbon dioxide emissions in comparison with different cultural groups, we see that in this case, as in previous, less developed countries show less $\mathrm{CO}_{2}$ emissions and also as in previous example, the reasons for this happening are the same - higher developed countries use more non-renewable energy by the amount when measuring in tons and therefore their $\mathrm{CO}_{2}$ emissions are higher. The hypothesis is again semi-denied, but again with proper reasons why.

Fig. 6 shows the measure of human development index and the state of natural resource depletion as a percent of gross national income (GNI) during the years 2010 - 2014.

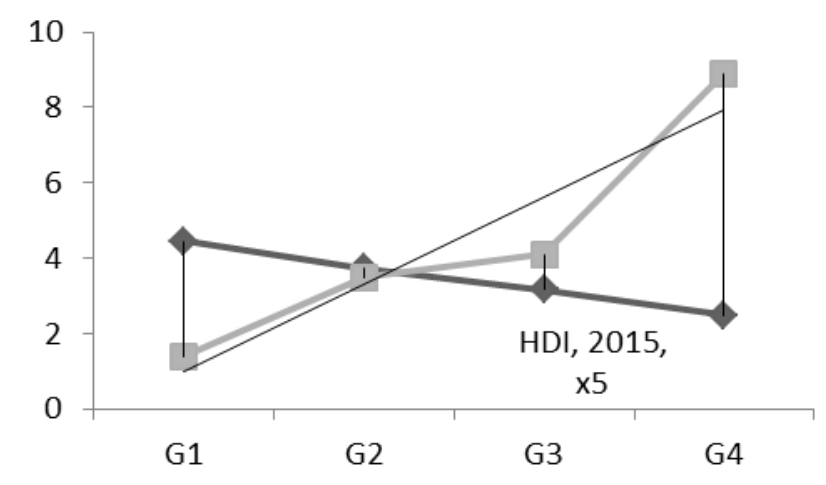

Fig. 6. HDI, 2015, x5 and Natural resource depletion, (\% of GNI), 2010-2014.

Since renewable energy cannot be depleted, natural resource depletion primarily shows the amounts of non-renewable energy sources that are depleted.

We see that comparing with percentage of gross national income, meaning how much countries in those cultures earn, and with the amount of natural resources depleted, higher developed countries have a better stance rather than less developed countries and cultures.

Even though previous 2 charts showed that higher developed countries use more non-renewable energy and produce more $\mathrm{CO}_{2}$, the resources comparing with how well people live, are lower in less developed countries.

One of possible explanations is the level of corruption in less developed countries, but then again corruption does exist at every country in a certain level. Another explanation is that higher developed countries buy resources from less developed countries for less and in exchange trade them produced goods for more.

Neither of the explanations can certainly explain this and therefore the hypothesis is proven correct in this case, that higher developed cultures, by all HDI standards, are superior to less developed countries and outplay them in the global aspect.

Fig. 7 shows the measure of human development index and research and development expenditures as a percent of gross domestic product (GDP) during the years 2005 - 2014 .

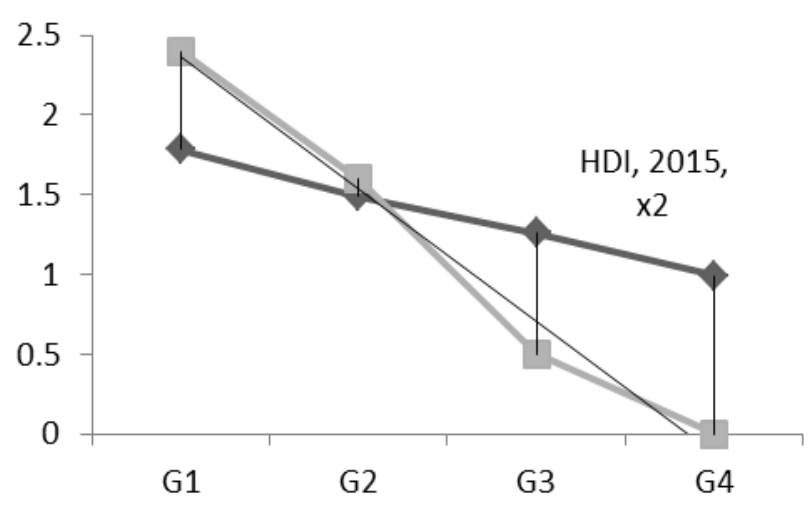

Fig. 7. HDI, 2015, x2 and Research and development expenditure, (\% of GDP), 2005-2014.

Research and development expenditure completely and directly shows the potential for renewable energy technologies to be developed and used.

In this case we see that higher developed countries spend considerably higher amount of \% of GDP towards research and development. It is a must to note that this not only applies to renewable energy technologies, but the research and development in global, yet the statistics show a tendency for each of the sections.

Another thing to mention is that higher developed cultures already have a higher GDP than less developed cultures therefore the percentage amount of higher developed cultures is even greater if converted into actual money flow that goes into research and development.

This proves the hypothesis and states that higher developed countries spend a considerably higher amount of their GDP towards new research and development projects.

Fig. 8 shows the measure of human development index and the percent of population that are 25 and older, and have at least some secondary education, during the years 2005 2015. 


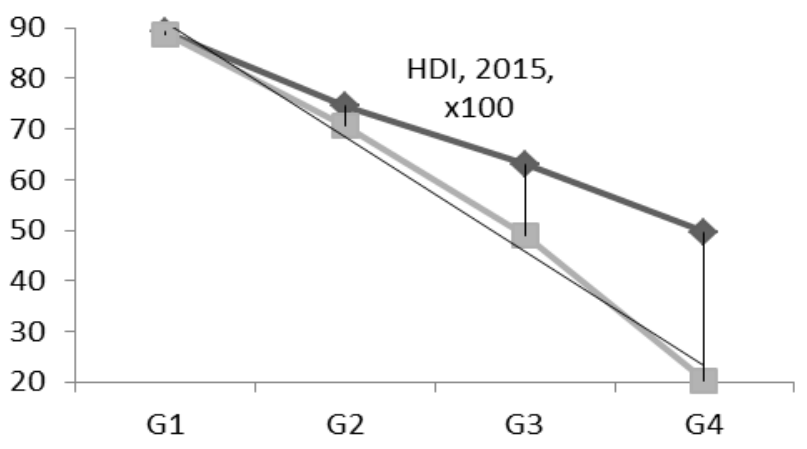

Fig. 8. HDI, 2015, x100 and Population with at least some secondary education, (\% ages 25 and older), 2005-2015.

Population with secondary education measurement has been picked because it would essentially show a certain direct level of scientific education within those cultures groups.

In this case, higher developed countries show a greater percentage of people with secondary education that are 25 and older. This chart clearly states that secondary education is much harder to achieve within less developed cultures compared to higher developed countries.

This measurement proves the hypothesis, because there are more barriers in less developed countries to achieve secondary education - lesser education quality, lesser graduation levels in global, etc.

After analyzing 6 different measurements, we can state that the result is positive in favor of higher developed countries and serves the hypothesis to be semi-correct.

\section{CONCLUSION}

1. Based on sociology's system theory, countries in the world have been differentiated into different cultural groups according to data provided by United Nations. The first group is very high developed culture (G1), second group is high developed culture (G2), third group is medium developed culture (G3) and fourth group is low developed culture (G4).

2. To understand about renewable energy technologies, they have been divided into 5 main groups: solar, wind, water, bio and others. After analyzing different renewable energy technologies, it has been learned that in order for cultures to accept them, they need to meet the minimum criteria. Minimum criteria has been identified as higher level of education, higher than average GDP balance science vise for innovations, the possibility to adapt the technologies for practice via natural availability within the culture.

3. Technology acceptance model has been used and modified with human development index measurements. Results proved and justified that both, the technology acceptance model and human development index, are in sync and therefore can be used together with each other.

4. With the knowledge of minimum requirements for renewable energy technologies, standard human development measurements have been picked. The following measurements have been analyzed: the change of HDI between groups 1 and 4; renewable energy consumption; carbon dioxide emissions; natural resource depletion; research and development expenditure; population with at least some secondary education.

5. After the analysis, a conclusion has been made that group 1 - very high developed culture is superior to accepting renewable energy technologies in regards with lower scale group 2 - high developed culture. The same conclusion has followed from top to bottom in regards to cultures in group 2, 3 and 4 . Nonetheless, the lower the group level, that culture has the highest level of potential to grow and reach the levels of higher groups. This means that the level of acceptance is essentially becoming exponential instead of being linear and that there are more cultures that are more equal now than they were before in global context.

\section{REFERENCES}

[1] G. Brundtland, M. Khalid, S. Agnelli, S. Al-Athel, B., Chidzero, L., Fadika, and M. Singh, "Our common future," ('brundtland reportl'), 1987.

[2] T. Kuhlman and J. Farrington, "What is sustainability?" Sustainability, vol. 2, no. 11, pp. 3436-3448, 2010.

[3] R. Wüstenhagen, M. Wolsink, and M. J. Bürer, "Social acceptance of renewable energy innovation: An introduction to the concept," Energy Policy, vol. 35, no. 5, pp. 2683-2691, 2007.

[4] I. Mikalauskas, "Economic, social and environmental benefits of smart grids, ” European Journal of Interdisciplinary Studies, vol. 7, no. 2, p. $19,2015$.

[5] G. Ritzer and J. Stepnisky, Modern Sociological Theory, SAGE Publications, 2017.

[6] S. Jahan, Human Development Report 2016: Human Development for Everyone, New York, NY 10017 USA: United Nations Development Programme, 1 UN Plaza, 2016.

[7] R. Ferry and E. Monoian, "A field guide to renewable energy technologies," Land Art Generator Initiative, 2012.

[8] REN 21, Renewables Global Status Report, 2015.

[9] F. D. Davis, R. P. Bagozzi, and P. R. Warshaw, "User acceptance of computer technology: A comparison of two theoretical models," Management Science, vol. 35, no. 8, pp. 982-1003, 1989.

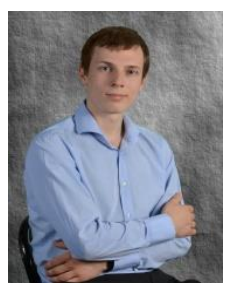

Ignas Mikalauskas is a BSc in electrical engineering at Kaunas University of Technology, MSc in international business management at Vilnius University and currently a $\mathrm{PhD}$ economics student at Vilnius University. Major field of scientific study includes sustainability, energy technologies and social acceptance.

He has completed an internship at Lithuanian Energy Institute and currently works in a logistics company in Klaipeda. Current research is the evaluation of social acceptance of energy technologies, creating a working scientific model in Lithuania regarding posing sustainability issues and continuous research towards societies, cultures, their social acceptance within the range of old and new renewable and non-renewable energy technologies.

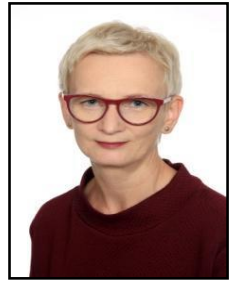

Asta Mikalauskiene was born on 31 January 1967 in Kaunas, Lithuania. She graduated from Kaunas University of Technology and holds $\mathrm{PhD}$ in Social Sciences (Economics).

Her main areas of research are climate change and environmental economics, sustainability assessment, multicriteria evaluation methods for energy and climate change policy, sustainable energy development measures for the implementation and monitoring.

Asta Mikalauskiene works in position of professor at Vilnius University. She is a head of Department of Business Economics and Management at Vilnius University; Kaunas Faculty. Scientists' works are published more than 10 papers in Web of Science referred international prestigious scientific journals and in a few monographs.

Scientist is a member of Energy Economics Association and member of the Lithuanian Department of Standardization Technical Committee. 